JAMA. 2016 May 24; 315(20): 2223-2224. doi:10.1001/jama.2016.4154.

\title{
Persistent Rash
}

\author{
Stacey A. Maskarinec, MD, PhD ${ }^{1}$ and Vance G. Fowler Jr, MD, MHS ${ }^{1,2}$ \\ ${ }^{1}$ Division of Infectious Diseases and International Health, Department of Medicine, Duke \\ University School of Medicine, Durham, North Carolina \\ ${ }^{2}$ Duke Clinical Research Institute, Duke University, Durham, North Carolina
}

\section{CASE}

A 50-year old man with a history of metastatic mucinous appendiceal adenocarcinoma presents for evaluation of a desquamating rash on his face that has spread to his scalp, inguinal region, and perineum over the past 4 months (Figure 1). The rash has been accompanied by diffuse alopecia of the face, scalp, axilla, and groin. There was no improvement in the rash despite multiple rounds of oral fluconazole, topical antibiotic ointment, and intravenous antibiotics. Prior to the development of his rash, he completed neoadjuvant chemotherapy followed by surgical resection. He underwent colostomy after he failed surgical correction for an enterocutaneous fistula, and he has required total parenteral nutrition (TPN) for the past year. He did not notice any significant changes in ostomy output during this time. Dermatological examination reveals widespread erythematous plaques on the face, scalp, and medial aspect of thighs bilaterally and scattered papules with scaling on face, scalp, chest, and back. Diffuse, non-scarring alopecia is present on the face, scalp, axillae, and groin.

\section{WHAT WOULD YOU DO NEXT?}
A. Perform skin biopsy
B. Obtain trace element levels
C. Prescribe topical steroid cream
D. Order a paraneoplastic panel

\section{DIAGNOSIS}

Acquired acrodermatitis enteropathica (AE)

B. Obtain trace element levels-The patient had acquired AE, a rare dermatologic condition caused by zinc deficiency. This patient developed acquired zinc deficiency in the setting of inadequate zinc supplementation in TPN. The patient had not received trace

Corresponding Author: Vance G. Fowler, Jr, MD, MHS, Division of Infectious Diseases and International Health, PO Box 102359 , Durham, NC 27710, Phone: 919-668-2549, Fax: 919-684-8902, vance.fowler@ duke.edu.

First Author:

Stacey A. Maskarinec, MD, PhD, stacey.maskarinec@dm.duke.edu 
elements for approximately one year due to a national shortage. The key to the correct diagnosis of acquired $\mathrm{AE}$ is the combination of desquamating rash coupled with alopecia in the setting of chronic supplemental alimentation. Although it is reasonable to consider a skin biopsy, a skin biopsy would not definitively establish the diagnosis. A paraneoplastic panel could be considered, but it would delay diagnosis, and the presentation is most consistent with nutritional deficiency. It is not appropriate to start a topical steroid cream until a diagnosis is determined.

\section{DISCUSSION}

The trace element zinc is important for several physiologic processes including enzymatic catalysis, gene regulation, and protein folding.' Zinc deficiency affects multiple organ systems and can occur genetically or be acquired secondarily. In humans, two gene families, ZnT (SLC30) and Zip (SLC39), encode transmembrane proteins that are expressed in the gastrointestinal tract and kidney and are responsible for zinc transport. A rare autosomal recessive disorder leading to zinc deficiency was mapped to a mutation in SLC39A4, located on chromosome 8q24.3 that encodes the Zip4 protein. A mutation in this transporter impairs zinc absorption in the duodenum and jejunum resulting in the observed deficiency. The estimated worldwide prevalence of genetic AE is 1 in 500,000 children with no race or gender preference.

More common than the genetic form of $\mathrm{AE}$ is the acquired form of $\mathrm{AE}$, which can occur in clinical conditions associated with compromised nutritional status such as alcoholism, inflammatory bowel disease, total parenteral nutrition, and states known to have high metabolic demands including severe burns and malignancy." The prevalence of dietary zinc deficiency is estimated at 20\% worldwide, and approximately 1-3\% in the United States. According to the American Society for Parenteral and Enteral Nutrition (ASPEN), there have been shortages of many PN products, including zinc, since 2010.' Zinc and other micronutrient deficiencies are also a major global health problem, with efforts by the United Nation Children's Emergency Fund (UNICEF) and the World Health Organization (WHO) to provide multiple micronutrient supplements to meet the required need for vulnerable populations.

The distinguishing clinical triad of AE includes diarrhea, alopecia, and periorificial (surrounding body orifices) and acral dermatitis.' The cutaneous manifestations range from scaly plaques to vesicular, pustular, bullous, or erosive lesions. Patients may also develop angular cheilitis. Cutaneous lesions are at high risk for secondary infection with skin flora. With prolonged nutritional deficiency, patients develop generalized alopecia and diarrhea. Zinc deficiency as also results in growth retardation, immune deficiency, anemia, thrombocytopenia, and dysgeusia.

$\mathrm{AE}$ is a clinical diagnosis, and laboratory analysis provides supporting evidence for the diagnosis. Zinc levels should be obtained in the morning to account for the fluctuation of zinc levels during the day and following meals. Concurrent low levels of alkaline phosphatase, a zinc-dependent enzyme, can also assist with the diagnosis. 
Treatment for both genetic and acquired AE is dietary supplementation. Elemental zinc is available in both oral and parenteral forms, and the recommended daily amounts range from 0.5 to $3 \mathrm{mg} / \mathrm{kg} /$ day for adults. Zinc levels should be monitored every 3-6 months. Lifelong therapy is needed for genetic deficiencies, and the duration of therapy for acquired deficiency depends on severity. Improvement in clinical symptomatology can be appreciated within days to weeks following zinc supplementation. Lastly, patients receiving TPN should receive clinical monitoring for other potential micronutrient deficiencies.

\section{PATIENT OUTCOME}

The patient had a zinc level of $29 \mathrm{ug} / \mathrm{dL}$ (normal range 56-134 ug/dL). He received zinc supplementation in his TPN, and within one month, the patient had complete resolution of rash and fatigue, and gradual return of hair growth (Figure 2). Repeat zinc level following supplementation was $90 \mathrm{ug} / \mathrm{dL}$. Although the patient recovered from his zinc deficiency, he later passed away.

\section{Acknowledgements}

Supported by grants R01-AI068804 and K24-AI093969 (VGF) and 5T32-AI052080-12 (SAM) from the National Institutes of Health.

Conflict of Interest Disclosures: VGF: reported serving as chair of Merck's V710 scientific advisory committee; receiving grant support and having grants pending from NIH, MedImmune, Actavis/Forest/Cerexa, Pfizer, Cubist/ Merck, Advanced Liquid Logics, Theravance, Novartis; serving as a paid consultant for Pfizer, Novartis, Galderma, Novadigm, Durata, Debiopharm, Genentech, Achaogen, Affinium, Medicines Co., Cerexa, Tetraphase, Trius, MedImmune, Bayer, Theravance, Cubist, Basilea, Affinergy, Contrafect; personal fees from Royalties (UpToDate), personal fees from Payment for development of educational presentations (Green Cross, Cubist, Cerexa, Durata, Theravance), and a patent pending on bacterial diagnostics.

Additional Contributions: We thank the patient's wife for permission to publish the patient's clinical information.

\section{REFERENCES}

1. Cousins RJ, Liuzzi JP, Lichten LA. Mammalian zinc transport, trafficking, and signals. The Journal of biological chemistry. Aug 25; 2006 281(34):24085-24089. [PubMed: 16793761]

2. Maverakis E, Fung MA, Lynch PJ, et al. Acrodermatitis enteropathica and an overview of zinc metabolism. Journal of the American Academy of Dermatology. Jan; 2007 56(1):116-124. [PubMed: 17190629]

3. Sehgal VN, Jain S. Acrodermatitis enteropathica. Clinics in dermatology. Nov-Dec;2000 18(6):745748. [PubMed: 11173209]

4. Kury S, Dreno B, Bezieau S, et al. Identification of SLC39A4, a gene involved in acrodermatitis enteropathica. Nature genetics. Jul; 2002 31(3):239-240. [PubMed: 12068297]

5. Lakdawala N, Grant-Kels JM. Acrodermatitis enteropathica and other nutritional diseases of the folds (intertriginous areas). Clinics in dermatology. Jul-Aug;2015 33(4):414-419. [PubMed: 26051055]

6. Prasad AS, Halsted JA, Nadimi M, Nutrition classics. The American Journal of Medicine, Volume 31, 1961. Syndrome of iron deficiency anemia, hepatosplenomegaly, hypogonadism, dwarfism and geophagia. Nutrition reviews. Jul; 1983 41(7):220-223. [PubMed: 6353293]

7. Mirtallo JM, Holcombe B, Kochevar M, Guenter P. Parenteral nutrition product shortages: the A.S.P.E.N. strategy. Nutrition in clinical practice : official publication of the American Society for Parenteral and Enteral Nutrition. Jun; 2012 27(3):385-391. [PubMed: 22513703] 
8. Hanson C, Thoene M, Wagner J, Collier D, Lecci K, Anderson-Berry A. Parenteral nutrition additive shortages: the short-term, long-term and potential epigenetic implications in premature and hospitalized infants. Nutrients. Dec; 2012 4(12):1977-1988. [PubMed: 23223000]

9. World Health Organziation. Preventing and controlling micronutrient deficiencies in populations affected by an emergency. 2007. http://www.who.int/nutrition/publications/micronutrients/ WHO_WFP_UNICEFstatement.pdf.

10. Jensen GL, Binkley J. Clinical manifestations of nutrient deficiency. JPEN. Journal of parenteral and enteral nutrition. Sep-Oct;2002 26(5 Suppl):S29-33. [PubMed: 12216717] 


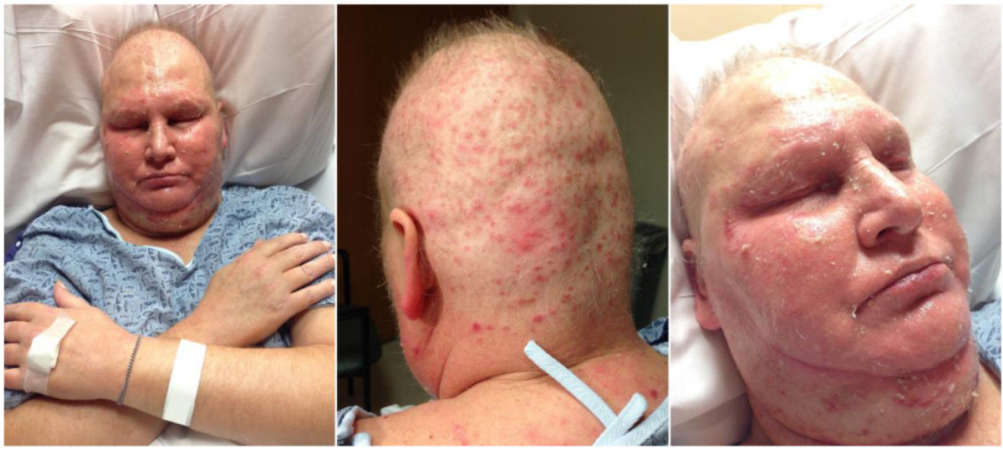

Figure 1.

Progression of generalized alopecia and erythematous, scaly rash involving face and scalp. 


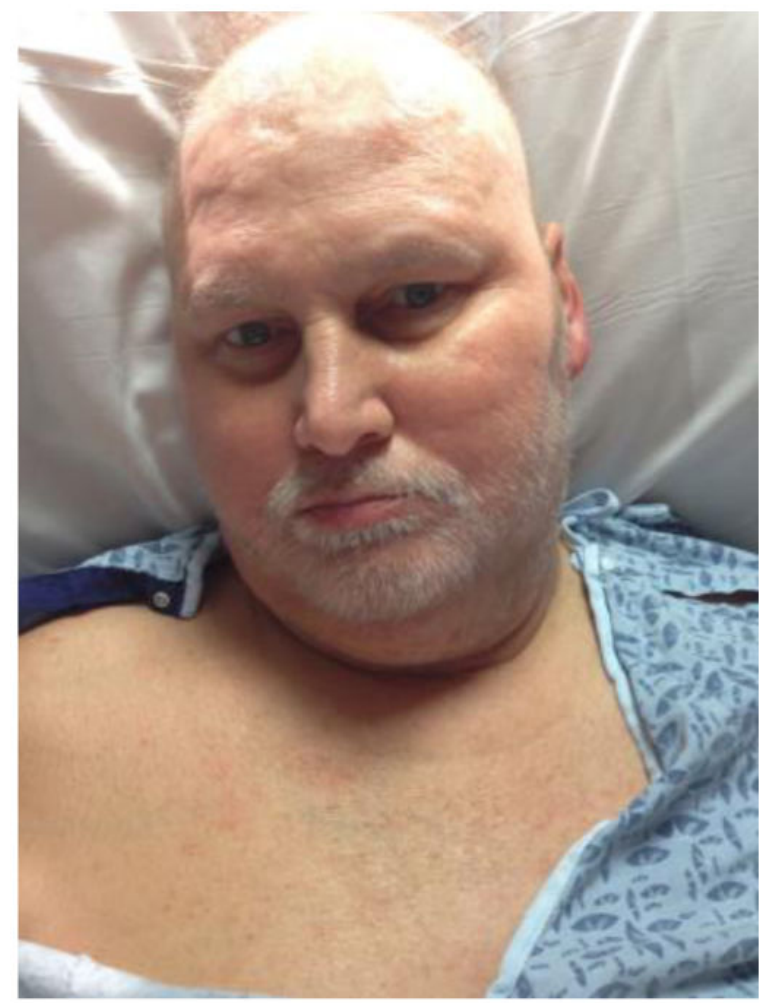

Figure 2.

Resolution of generalized alopecia and rash following zinc supplementation. 